\title{
The Effects of Environmental Problem-based Learning Method on Malaysian Primary ESL Learners' Vocabulary Achievement
}

\section{Zachary Farouk Chai and Suyansah Bin Swanto \\ Universiti Malaysia Sabah, Malaysia}

Abstract: Environmentaleducation has long been introduced as early as the 18th century in western countries, but in Malaysia, it still can be considered as a new start in the year 1979. In relation to this, various programs have been conducted by the government to produce literate individuals that are aware of and concern of environmental issues. In primary English education, there are a few topics on the environment that should be taught by teachers, and environmental education is also considered as a cross-curricular subject. The present study aimed to investigate the effects of environmental problem-based learning $(P B L)$ on Malaysian primary school learners' vocabulary achievement. Environmental PBL is an instructional method that provides learners the opportunities to learn cooperatively in groups to find solutions to any problem. This study employed experimental design, which involved 20 learners that came from an intermediate level of English proficiency. They were randomly divided into experimental group and control group. The experimental group was treated with environmental PBL in learning new vocabulary, while the other group was taught using the conventional memorisation method. A set of vocabulary test (pre and post) was used to measure learners' vocabulary achievement and the data were analysed by using independent sample t-test. From the data, it was found out that the learners who were taught by using environmental PBL improved their vocabulary acquisition significantly as being compared to the control group based on the means of marks obtained by the research participants in the experimental group with 12.80 and the mean achieved by the control group with 6.20. Next, this study also showed how environmental PBL helped the experimental group in learning vocabulary based on their orientations which included two themes (effectiveness and participation). Hence, it is suggested that English teachers should use environmental PBL as an effective method of teaching vocabulary to young learners.

Keywords: Environmental Problem-based Learning Method, ESL Learners, Vocabulary Achievement

\section{INTRODUCTION}

Babcock (1993) states that successful language learning involves the same successful combination of acquired micro and macro skills in terms of proper language inputs and environmental problems, both of which are a rich source for language acquisition materials. By referring to this, learning English would become more meaningful if teachers are able to integrate environmental education into any lesson. This also extends to vocabulary instruction, which is an important aspect of 
English language mastery. The acquisition of vocabulary is generally an integral part of learning English. It is expected that learners will master all language skills such as listening, speaking, writing, and reading in English. Therefore, it is necessary to acquire English vocabulary in order to be good users in all these skills. In learning English, vocabulary is one of the most significant language components (Nation, 2001). Vocabulary learning can help English language learners to learn and help them to master the other components of the language. Thornbury (2002) says that a lack of vocabulary hinders linguistic understanding and production. Without a strong knowledge of vocabulary in English, the transmission and reception of information could not be achieved in a coherent manner. In order to improve the quality of teaching and attract the attention of learners to learn new vocabulary, teachers need to develop a variety of teaching strategies and techniques. This is very important to ensure that vocabulary teaching is effective and fluent in accordance with the learning standards set out in the curriculum.

There are many learning strategies proposed by the Ministry of Education Malaysia based on the Malaysian Standard Document for Curriculum and Assessment (DSKP), one of which is problem-based Learning (PBL). It is a teaching strategy that applies a student-centred approach, and learners are expected to solve a problem that teacher has raised through the use of their thinking skills. Ilter (2004) said PBL is a successful way of developing creativity and positive environments for learners and that this approach helps them to learn social concepts by undertaking small projects with their peers. By examining the advantages and efficiency of using PBL in English language education, this study was designed to explore the effectiveness in improving learners' vocabulary by an intervention called environmental Problems-based Learning. Environmental Problem-based Learning means applying PBL to teaching and learning the English language through the integration of environmental resources.

In the $21^{\text {st }}$ century world of education, environmental education and language learning work simultaneously. This requires appropriate learning approaches and methods to achieve the learning standards of language learning in the curriculum, as well as the purpose of encouraging learners' awareness of the environment can be achieved effectively. In primary school education, the need to integrate environmental education has been established by Curriculum Development Centre, Ministry of Education Malaysia in the Standard Document for Curriculum and Assessment (DSKP) in which the current curriculum content is expected to develop awareness towards the love of the environment in the learners' lives (Ministry of Education, 2012). In English language subject, environmental education is integrated as parts of the learning content in which some of the topics learned by the learners are on awareness of the environment. Environmental education is embedded with environmental knowledge, proficiency, skills, and nurturing positive values and attitudes (Azlinawati et al., 2018).

Throughout the years of studying in primary school, learners are required to learn basic vocabulary, which comprises items such as nouns, verbs, adjectives, conjunctions, prepositions, and others. As a result, vocabulary plays a predominant role for the learners to construct sentences and giving speeches in the English language. However, one of the existing problems in vocabulary understanding was most of the learners did not understand the meaning of certain vocabulary in 
passages. This is also known as unknown words, and these words appear in textbooks or other supporting materials such as posters, stories and poems (Kinsella et al., 2014). Those words still become one of the significant obstacles in understanding the content conveyed, probably due to the insufficient vocabulary knowledge of the learners as ESL learners. For instance, based on the researcher's experience, when he had the learners read and understand the content of a passage, most of them said that the text was difficult to comprehend since there were many unknown words found in the passage. They could not understand new words appearing in sentences or passages. The most obvious weaknesses of the learners lay in the area of grammar and their vocabulary knowledge especially in writing parts which mainly caused by the fact that their environment does not encourage the use of language in the effort of acquiring the language skills (Hashimah et al.: 112, 2008).

There were many studies conducted on the effectiveness of Problem-based Learning (PBL), especially in teaching English language to ESL learners. However, the application of environmental education in PBL is rather limited. These studies were done by Essien (2018) who investigated the effectiveness of applying PBL in improving ESL learners' speaking skilks and Beckett (1999) who studied teachers' views and perceptions on the implementation of PBL in ESL classrooms. These two studies only focused on the use of PBL in language teaching using different topic aside from environments. However, another study was conducted by Dyah Christina Iswandari et al., (2017) who evaluated the effectiveness of using environmental PBL in language teaching but this study only focused on learners' writing skills. Hence, this study aimed to investigate the effectiveness of Environmental Problem-based Learning, particularly in enhancing ESL learners' English vocabulary achievements. In this study, the researcher integrated the elements of environmental education with PBL as an intervention in imrpoving the Malaysian primary school ESL learners' vocabulary achievement. Incorporating the environment education to ESL classes through PBL could enrich the students' vocabulary related to the environment since learning to use the language and using the language to learn to happen simultaneously.

Dyah Christina Iswand ari et al., (2017) conducted a study on the integration of environmental education with problem-based learning methods to improve the vocabulary acquisition and writing skills of students. The quasi-experimental design of the study involved two classes of senior high school students, each consisting of 30 students and assigned to the experimental group and control group. The treatment used in this study was the experimental group's intervention of environmental PBL, and conventional teaching method was given to the control group. Treatment in the experimental class was conducted at five meetings where students had time to analyse the problems that had arisen and find solutions to these problems and this set of procedures involved vocabulary related to the environment. In short, the vocabulary has been studied in context through PBL. The results of the study showed that the experimental group performed better than the control group based on their post-test achievements. To conclude, this study has shown that teaching by environmental PBL involving eleventh grade Indonesian EFL students has had a significant impact on the achievement of environmental vocabulary and writing skills. This study provided insights on how the PBL and environmental 
vocabulary were effective to increase senior high school writing skills. The current study used the same approach to improve vocabulary acquisition among Malaysian ESL learners.

Next, Essien (2018) performed one study to determine the impact of projectbased learning on students ' English language abilities. This study consisted of 81 students from the third year of English major students from Bangkok, Thailand. The majority of research participants improved significantly by implement ing the Project-based Learning Method in English Language Teaching. Specifically, 80\% of students scored above average in the post-test period compared to only $20 \%$ in the pre-test period. In this study, the majority of subjects also determined that PBL had improved its critical thinking skills, independent learning skills, personal and social responsibility, and strong communication skills. In conclusion, the results of the study are a key pointer for ESL educators to deploy Project-Based Learning as a teaching methodology to enhance students' ability to speak English. The impact of project-based learning on students ' English language abilities was focused on language skills which were speaking skills rather than on the language items and hence this study was carried to investigate vocabulary acquisition of ESL learners.

In addition, another study was carried out by Beckett (1999) to investigate the implementation of the Project-based Instruction in Canadian second ary schools. The main aim of the study was to investigate the goal of ESL teachers for PBL, and the evaluation of project-based instruction by ESL teachers and students. The results of the data collected in this study are based on two main techniques, observations, and interviews. Consequently, the results indicated that PBL was highly favoured by ESL teachers because it allowed them to take an integrated approach to language teaching in the ESL classroom. The discussions also showed that PBL enabled them to foster critical thinking and problem-solving skills, which could facilitate independent learning and cooperative learning. Also, in this study, they evaluated project-based instruction favourably because they thought that learning English functionally provided contexts for their students. Thus, this study only focused on the teachers' views and perceptions on the implementation of PBL in an ESL classroom and thus the currect study was conducted to evaluate the effectiveness of the intervention by using a different design which was experimental design.

This study provides some positive impacts on education. Firstly, school plays an important role in providing learners the knowledge and skills for them to be able to use the language in a variety of contexts. In relation to this, the Common European of Reference for Languages of CEFR has been implemented by the Malaysian government starting from 2013 to cater to the needs of language learners as well as particular aspects related to teaching and learning of the English language. Unfortunately, the level of mastery among ESL learners, especially for those who live in rural areas, has been a serious issue over the past decades. The main cause of this issue is the lack of practice among ESL learners in their daily life. Based on this reality, an appropriate approach, method, and teaching materials have to be selected. Thus, the results of the research are expected to give some theoretical contributions to the school to develop the quality of education as well as encouraging the school administers to devise interesting activities by applying PBL in English lessons with the aim to enable students to compete and explore new 
knowledge nationally and internationally. PBL activities will help the school to provide new and enjoyable learning atmosphere for the learners especially in developing language skills.

Seconly, the results of this research are expected to become a reference for other teachers who want to conduct a further research on the similar problems, by using another design, such as an experimental research which is by selecting rand om samples from different age or school to develop the learners' und erstanding of certain vocabulary based on their level of proficiency. Next, ESL teachers also can use PBL approach to teach English subject to their learners. In applying PBL to the learning context, teachers have to choose an appropriate topic to enable learners to use their thinking skills and communication skills in finding solutions for any issues or problems. Finally, the results of the research are useful for the learners as information to know their vocabulary mastery, so they can improve it because of its importance to be mastered to support the improvement of their language skills. The results of this study would give some insights and ideas on how learners from different level of education can use PBL as an independent learning technique in improving their vocabulary knowled ge. Hence, this study is imperative to give the learners the knowledge on how they can learn vocabulary in a constructively with or without teacher's assistance.

Thus, the students have the opportunity to learn language instructions, and at the same time, experience real-life education. This study aimed to achieve the following objectives; (i) to measure the effectiveness of Environmental Problembased Learning on ESL learners' vocabulary achievements; and (ii) to find out learners' orientations towards the use of Environmental Problem-based Learning in learning vocabulary. Next, the following were the research questions that this study aimed to answer;

1) What are the effects of Environmental Problem-based Learning to ESL learners' vocabulary achievements?

2) What are the learners' orientations towards the use of Environmental Problem-based Learning in vocabulary?

\section{METHODOLOGY}

This study employed an experimental design of pre-test and post-test. In this design, the participants were randomly assigned to the experimental group and control group. Both groups were pretested and the experimental group undertook the treatment and finally, both groups were post-tested to examine the effectiveness of the intervention used. Basically, the data was collected in July to August, 2019 in one primary school, which is located in Sabah, Malaysia. The school was selected based on their locality in the suburban area of Semporna, Sabah. To triangulate the data of this study, multiple groups were included to answer the research questions set earlier. In addition, the research participants of this study were Malaysian Year 5 ESL primary learners who learned the English language as their second language at school. The proficiency level of the learners ranged from low to intermediate, and this categorisation was based on their examination results. The research participants were chosen using random sampling. In random sampling, the research 
participants were selected entirely by chance, and each member of the population has an equal chance of being included in the sample (Easton \& McColl, 1997).

Furhtermore, this study applied two instruments. Firstly, this study made use one vocabulary test to evaluate the learners' achievement in vocabulary acquisition. The test used was a cloze-based test with four sections of questions. Each section contained one cloze-passage where the research participants were required to fill in the blanks with appropriate words. One general picture was given to each cloze-passage, and this was to aid the research participants to make a connection. Next, for each blank, three options of answers were provided to the research participants. They had to choose the correct answer to fill in the blanks. The topics/themes of the vocabulary test were taken from the Year Five English textbook. For this study, the test paper for both pre and post was similar. The pretest was basically used to find the students' vocabulary mastery level before the intervention being conducted. The post-test scores were used as a means of comparison to know the learners' progress after the treatment was given to the experiment group. The next instrument used in this study was structured-interview. A semi-structured interview was carried to the research participants to obtain more information regarding the intervention used in this study. Five research participants were selected randomly to be interviewed by the researcher after the intervention. The structured-interview consisted of five open-ended questions, and these questions were meant to answer the second research question. During the interview, a set of standardised questions were asked to the research participants. The responses or answers received during the interview sessions will be recorded in writing form.

This study had been conducted from July, 2019 to August, 2019 in one of the primary schools in Sabah, Malaysia. Before conducting this study, the researcher had applied permission from the school authority. Next, the researcher carried out the pre-test to all the research participants from two different classes. The research participants were given 40 minutes to answer the test. Then, each class was assigned as an experimental and control group. The experimental group involved in the treatment for five weeks period, with the allocation of two hours per week. Hence, the total hours of treatment was 8 hours. On the contrary, the control group followed the conventional way of learning vocabulary without any special treatment. After the intervention session was completed, both groups answered the post-test with similar questions and time as in the pre-test. To ensure the interreliability of the data, the tests were marked by the researcher and two other teachers to check for research participants' achievement in the test. After the research participants answered all the tasks given, 5 out of 10 research participants were selected randomly to be interviewed regarding their orientations on the effectiveness of Environmental PBL. They were interviewed in a group.

As mentioned earlier, to evaluate the effects of using Environmental Problem-based Learning on ESL learners' vocabulary achievements, this study used one set of vocabulary test as a pre-test and post-test instrument. The vocabulary test' marks obtained by the research participants were analysed using IBM SPSS (Version 23) software. Then, the mean scores between the pre-test and post-test were compared for both experimental and control groups. The mean scores and the results of the independent-samples t-test (or independent t-test, for short) were 
reported as the researchers wanted to compare the means between two unrelated groups on the same continuous, dependent variable. Furthermore, the data gathered from the semi-structured interview was analysed by categorising the information gathered by dividing them into two themes. The data was analysed in written form, and descriptive statements were recorded in order to answer the research questions. Member checking was also performed, with other teachers asked to read through the transcripts and preliminary data analysis to ensure the accuracy and reliability of the interpretations made.

\section{FINDINGS AND DISCUSSIONS}

Effects of Environmental Problem-based Learning on ESL learners' vocabulary achievements

As mentioned earlier, to evaluate the effects of using Environmental Problem-based Learning on ESL learners' vocabulary achievements, this study used one set of vocabulary test as a pre-test and post-test instrument. The marks obtained by the research participants were then analysed using IBM SPSS (Version 23). In order to evaluate the effects of using the intervention on learners' vocabulary achievement, the scores of the pre-test and post-test from both experimental and control groups were compared by using independent sample t-Test.

First and foremost, the results of the pre-test for both groups did not show any significant difference as the research participants had similar proficiency levels of vocabulary acquisition based on their examination results before the intervention had being carried out. Table 1.0 and Table 2.0 show a lack of any significant in the pre-test for both experimental and control groups.

Table 1. Descriptive Statistics for Pre-Test of Two Groups (Experimental and Control)

\begin{tabular}{|c|c|c|c|c|}
\hline Participants & N & Mean & Std. Deviation & Std. Error Mean \\
\hline Experimental & 10 & 7.4000 & 3.40588 & 1.07703 \\
\hline Control & 10 & 7.1000 & 2.75882 & .87242 \\
\hline
\end{tabular}

Based on Table 1, the means obtained for both experimental and control groups do not depict any significant comparison in the pre-test in which the experiment group's mean was 7.40 and the control group's mean was 7.10 and this concluded that both groups were homogenous before the intervention was conducted by the researchers.

Table 2. Independent t-Test to Show the Difference Between Two Groups in PreTest. 


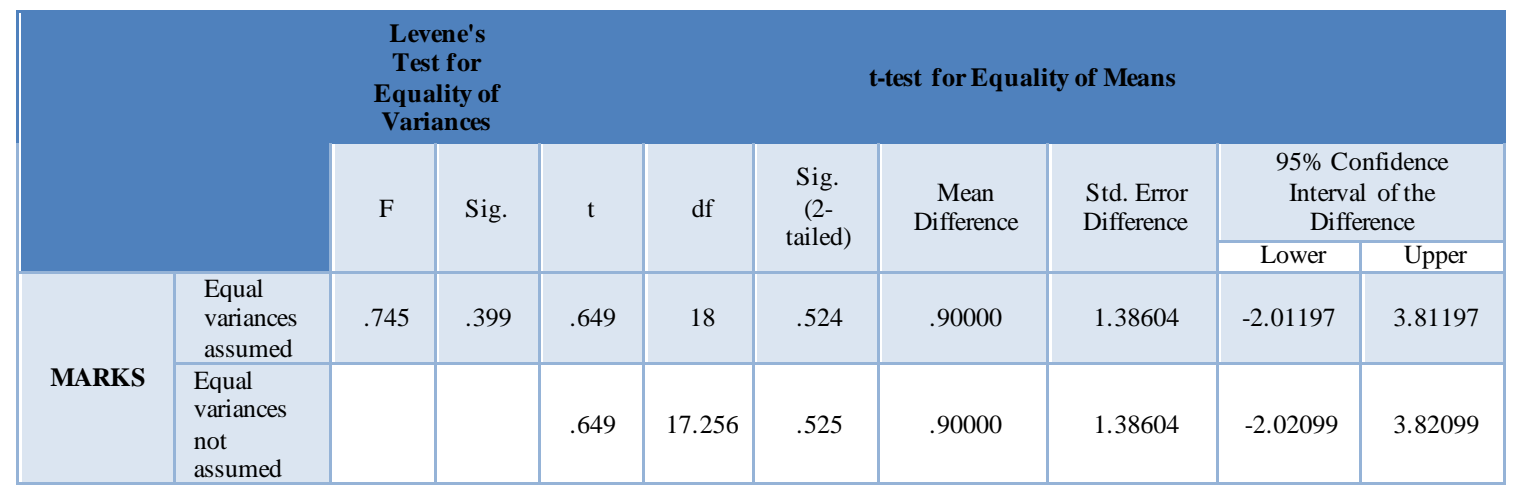

Data in Table 2 indicate a lack of any significant difference between the experimental group and the control group in vocabulary pre-test, which confirms that the two groups were homogeneous before the intervention has been carried out (p-value $=0.524>0.05)$.

On the contrary, the results of the post-test obtained by the experimental group are significant as being compared to the control group. Table 3 shows the comparison of analysis between experimental and control groups in the post-test conducted.

Table 3. Descriptive Statistics for Post-Test of Two Groups (Experimental and Control)

\begin{tabular}{|c|c|c|c|c|}
\hline Participants & $\mathbf{N}$ & Mean & Std. Deviation & Std. Error Mean \\
\hline Experimental & 10 & 12.8000 & 3.64539 & 1.15277 \\
\hline Control & 10 & 6.2000 & 2.52982 & .80000 \\
\hline
\end{tabular}

Table 4. Independent t-Test to Show the Difference Between Two Groups in PostTest.

\begin{tabular}{|c|c|c|c|c|c|c|c|c|c|c|}
\hline & & $\begin{array}{l}\text { Leven } \\
\text { for } \mathrm{E} \\
\text { of } \mathrm{Va}\end{array}$ & $\begin{array}{l}\text { Test } \\
\text { lity } \\
\text { nces }\end{array}$ & \multicolumn{7}{|c|}{ t-test for Equality of Means } \\
\hline & & \multirow[t]{2}{*}{$\mathrm{F}$} & \multirow[t]{2}{*}{ Sig. } & \multirow[t]{2}{*}{$\mathrm{t}$} & \multirow[t]{2}{*}{ df } & \multirow[t]{2}{*}{$\begin{array}{l}\text { Sig. } \\
(2- \\
\text { tailed })\end{array}$} & \multirow[t]{2}{*}{$\begin{array}{c}\text { Mean } \\
\text { Difference }\end{array}$} & \multirow[t]{2}{*}{$\begin{array}{l}\text { Std. Error } \\
\text { Difference }\end{array}$} & \multicolumn{2}{|c|}{$\begin{array}{l}\text { 95\% Confidence } \\
\text { Interval of the } \\
\text { Difference }\end{array}$} \\
\hline & & & & & & & & & Lower & Upper \\
\hline \multirow{2}{*}{ MARKS } & $\begin{array}{c}\text { Equal } \\
\text { variances } \\
\text { assumed }\end{array}$ & 2.270 & .149 & 4.704 & 18 & .000 & 6.60000 & 1.40317 & 3.65205 & 9.54795 \\
\hline & $\begin{array}{c}\text { Equal } \\
\text { variances } \\
\text { not } \\
\text { assumed }\end{array}$ & & & 4.704 & 16.037 & .000 & 6.60000 & 1.40317 & 3.62596 & 9.57404 \\
\hline
\end{tabular}

Based on Table 3 and Table 4, the mean of marks obtained by the research participants in the experimental group is 12.80 and the mean achieved by the control group is 6.20. The difference (6.60) of means obtained by both groups shows that 
the experimental group had achieved significantly in the post-test as being compared to the control group after undergoing Environmental Problem-based Learning Method and hence this answers the first research question. Besides, the results of the independent $t$-test $(\mathrm{t}=4.704, \mathrm{P}<0.05)$ indicate that there is a significant difference between the experimental and control groups' mean scores on the posttest of vocabulary testing.

The main finding of this study indicated positive answers to the research questions. It was found that the Environmental PBL had positive effects on the achievement of vocabulary among the ESL learners of school ' $\mathrm{x}$ '. This was proven through the higher mean score that the experimental group obtained in the post-test. Specifically, the experimental group's performance was more prominent than the control group in the vocabulary post-test. Furthermore, the pre-test results for both groups did not reveal any statistically significant difference between the two groups of learners. This means that before the application of the experiment both groups had nearly similar performance. That is to say, they had the same background knowledge. The main finding of this study is in line with a research done by Dyah Christina Iswandari et al., (2017) on the integration of Environmental Education with Problem-based Learning Method which improved students' vocabulary acquisition as the students as they managed to contextualise the words learned in variety of contexts in solving the problem given. The finding based on the marks obtained by the experimental group in this study also shows that the implementation of PBL helps learners to construct knowled ge and enhance their learning experience especially in learning language components such as grammar, idioms, literature and vocabulary (Tai \& Yuan, 2007). To wrap up, learners who undertake Environmental PBL in learning new vocabulary can improve their learning rather than learning in a conventional way such as by using memorisation technique.

\section{Learners' orientations towards the use of Environmental Problem-based} Learning in vocabulary?

To answer the second research question with the aim to clarify the use of Environmental Problem-based Learning Method in enhancing learner's vocabulary achievement, this study employed semi-structured interview. There were five research participants selected randomly from the experimental group to be involved in the interview session. The results of the interview were discussed based on the themes of effectiveness and motivation. The first question asked to the research participants was "Did you enjoy learning new vocabulary in the activity?" For this first interview question, all the learners agreed that they had enjoyed learning new vocabulary in the English lesson by involving in Environmental Problem-based Learning Method. During the semi structured interview, most of them reported that they had fun in learning new words by using Environmental PBL Method.

\section{Effectiveness}

The second interview question posed to the research participants was "Why do you think that the activity is effective in learning new vocabulary". Two of the total participants responded that "I think that the activity is effective as my friends and I were able to discuss the given problem as well as find solutions to solve the problem given". Next, the other participants stated that they could remember the word s learned in the lesson because they were familiar with their usage in different 
contexts in the group activity. This particular finding is supported with a study conducted by Essien (2018) who found out that PBL had positive impacts on students' language abilities such as learning skills, thinking skills and communication skills. The finding is also supported by Schmidt et al., (2001), who claimed that PBL process allows students to construct new knowledge with a deeper understanding and better retention of language knowledge as they have evaluated suggested ways to solve the problem. Next, they also added that they could memorise the meaning of words as they used pictures and actions in the PBL activity. They stated that words they learned were repeated in the activity conducted, and different texts provide a context that helps them figure out the meaning of words they do not know. In vocabulary learning and assessment, visual aids and learning through doing help learners remember important information and retain as much knowledge learned previously in the teaching process (Ghulam Shabiralyani et al, 2015). Apart from that, they also pointed out the effectiveness of using mind-map in the lesson has helped them to memorise new words as they have to write down the words and their respective meaning as well as sentences that contain that particular from the given passage. As a result, this contextualized learning stimulates their understanding of words and they learn which words go together as well.

\section{Participation}

The third interview question asked to the research participants was "How does the activity affect your participation in learning new vocabulary?". Three out of the five learners claimed that "We participated really well in learning new vocabulary as we had to solve the problem given on the current environmental issue by the teacher." They also added that the idea of integrating environmental topics with PBL helped them to memorise the meaning of new words as they used the words many times in communicating with their group members. One of the participants also added "My friends and me were actively enjoyed in the activity as we had the chance to discuss and share what we have discussed with other groups". The findings of the interview question is accordance to the previous literature in which Beckett (1999) found out that the implementation of PBL enabled ESL learners to learn cooperatively as contexts were functionally provided to them. Next, another study also supported the finding in which Deham \& Mohammad, (2010) argued that Project-based Learning unit engaged the lowest and highest students as well as those students who were least interested in their classes' activities as they were able to participate in active discussion to solve any issue or problem. This is accordance with Barrows (1985), who argued that PBL approach represents a fundamental shift from a fixed knowledge base by the teacher himself to the facilitation of students' activity construction of knowledge through collaborative problem solving among students in one classroom to memorise better on the learning content. Hence, Environmental PBL improved the learners' participation in teaching and learning activity which is an important element in learning new vocabulary as they have to be active learners.

\section{CONCLUSIONS}

As conclusion, this study has revealed that the use of environmental problem-based learning (PBL) is significant in increasing primary school learners' vocabulary achievement, as suggested in the curriculum. In this study, the marks of 
the learners who learned new vocabulary by using Environmental PBL had improved in the post-test as being compared to the pre-test. Hence, a considerable improvement in their vocabulary was found. To clarify the achievement of the learners, the information gained from the interview session was used to prove the aspects or features of the intervention that helped learners to understand and able to contextualise the targeted vocabulary in a variety of forms. Apart from that, this study highlights the importance of environmental education has led in teaching and learning process as English education is one of the medium to create awareness on the issues of environment that need to be understood even by young learners as they will hold the future of our country when they grow up. The role of English language learning is able to bring this content knowled ge to the realm of language learning, for both language and content knowled ge will work simultaneously (Cates, 2009). Through Environmental PBL, the learners were directed to work collaboratively to find solutions of the real problems in their lives in English learning in the classroom.

This study can be replicated to find out whether the same result is taken with different context, design or method. The research covered a limit number of learners because this research was participated by the researcher's learners in ordinary classes. For other researchers who conduct any research in other designs or types such as experimental research or action research, they can explore more on Environmental PBL as an effective and appropriate method to teach English language skills or items in an ESL classroom. Moreover, they can do further research on this topic in the future with different sets of vocabulary of different ages of research participants. Lastly, other researchers can run the intervention with their students of other levels, such as a secondary school with different sets of vocabulary to find out whether the same results will be taken.

\section{REFERENCES}

Abdalla, M. E., \& Gaffar, A. M. (2011). The Seven Steps of PBL implementation. KSA: Jazan University.

Abdullah, A., Zakaria, S. Z. S., \& Razman, M. R. (2018) Environmental education through outdoor education for primary school children. International Journal of the Malay World and Civilisation, 6(1),27-34.

Babcock, J. C., Waltz, J., Jacobson, N. S., \& Gottman, J. M. (1993). Power and violence: The relation between communication patterns, power discrepancies, and domestic violence. Journal of Consulting and Clinical Psychology, 61(1), 40-50. http://dx.doi.org/10.1037/0022-006X.61.1.40

Barrows, H. S. (1985). How to design a problem-based curriculum for the preclinical years. New York, NY: Springer Publishing Company, Inc.

Beckett, G. B. (1999). Project-based instruction in a Canadian secondary school's ESL classes: Goals and evaluations. Unpublished doctoral dissertation,University of British Columbia.

Cates, K. A. (2009). Teaching for a better world: global issues and language education.Retrieved from www.hurights.or.jp/pub/hreas/5/06cates.pdf. 
Deham, S. H., \& Mohammed, M. Wiam. (2010). Iraqi EFL learners' Performance in English Spelling. Journal of Social Science and Education 3(233-248).

Easton, V. J. \& McColl, J. H. (1997). STEPS Statistics Glossary. Retrieved from http://www.stats.gla.ac.uk/steps/glossary/

Iswandari, D. C., Prayogo, J. A., \& Cahyono, B. Y. (2017). Effect of Environmental Problem-based Learning on the Indonesian EFL Students' Environmentrelated Vocabulary Mastery and Writing Ability. Theory and Practice in Language Studies, 7(8), 608-616.

Jalaluddin, N. H., Awal, N. M., \& Bakar, K. A. (2008). The mastery of English language among lower second ary school students in Malaysia: A linguistic analysis. European Journal of Social Sciences, 7(2), 106-119.

Nation, I. S. P. (2001). Learning Vocabulary in Another Language. Cambridge University Press: Edinburgh.

Shabiralyani, G., Hasan, K S., Hamad, N \& Iqbal, N. (2015). Impact of visual aids in enhancing the learning process case research: District Dera Ghazi Khan. Journal of Education and Practice, 6(19), 226-233.

Tai, G. X. L., \& Yuen, M. C. (2007). Authentic Assessment Strategies in Problem Based Learning. Singapore: Journal Thornbury, 18, 14-16. 